\title{
Functional genomics to identify the factors contributing to successful persistence and global spread of an antibiotic resistance plasmid
}

\author{
Jennifer L Cottell ${ }^{\dagger}$, Howard TH Saw ${ }^{\dagger}$, Mark A Webber and Laura JV Piddock
}

\begin{abstract}
Background: The spread of bacterial plasmids is an increasing global problem contributing to the widespread dissemination of antibiotic resistance genes including $\beta$-lactamases. Our understanding of the details of the biological mechanisms by which these natural plasmids are able to persist in bacterial populations and are able to establish themselves in new hosts via conjugative transfer is very poor. We recently identified and sequenced a globally successful plasmid, pCT, conferring $\beta$-lactam resistance.

Results: Here, we investigated six plasmid encoded factors (tra and pil loci; rci shufflon recombinase, a putative sigma factor, a putative parB partitioning gene and a pndACB toxin-antitoxin system) hypothesised to contribute to the 'evolutionary success' of plasmid pCT. Using a functional genomics approach, the role of these loci was investigated by systematically inactivating each region and examining the impact on plasmid persistence, conjugation and bacterial host biology. While the tra locus was found to be essential for all $\mathrm{pCT}$ conjugative transfer, the second conjugation (pil) locus was found to increase conjugation frequencies in liquid media to particular bacterial host recipients (determined in part by the rci shufflon recombinase). Inactivation of the $\mathrm{pCT}$ pndACB system and parB did not reduce the stability of this plasmid.
\end{abstract}

Conclusions: Our findings suggest the success of pCT may be due to a combination of factors including plasmid stability within a range of bacterial hosts, a lack of a fitness burden and efficient transfer rates to new bacterial hosts rather than the presence of a particular gene or phenotype transferred to the host. The methodology used in our study could be applied to other 'successful' globally distributed plasmids to discover the role of currently unknown plasmid backbone genes or to investigate other factors which allow these elements to persist and spread.

Keywords: Beta-lactam, ESBL, Mobile genetic element, Plasmid, Recombination

\section{Background}

Plasmids have been indispensable tools in the development of molecular biology and much of our understanding of their biology has been based on a small number of model replicon transmissible elements. However, less is known about natural plasmids and in particular, the interplay between plasmids and their host strains. Bacterial plasmids are widely recognised for their role in the expansion and dissemination of virulence and antibiotic resistance genes both between

\footnotetext{
* Correspondence: I.j.v.piddock@bham.ac.uk

${ }^{\dagger}$ Equal contributors

Institute of Microbiology and Infection, School of Immunity and Infection, The College of Medical and Dental Sciences, The University of Birmingham, Birmingham B15 2TT, UK
}

members of the same species and to new bacterial hosts of different species $[1,2]$. Their ability to acquire and spread either single or multiple antibiotic resistance genes to pathogens has become a considerable problem and an obstacle to successful therapeutic treatment [3]. This is compounded by the lack of development of new effective antibiotics, particularly against infections caused by Gram negative bacteria with plasmid mediated antibiotic resistances, which are causing significant global clinical problems [4]. The recent emergence of genes including $\beta$-lactamases which confer resistance to the commonly used $\beta$-lactam class of antibiotics, can largely be attributed to the spread and persistence of successful plasmids in a wide range of bacterial hosts [5-7]. However, despite their importance and the 
recently generated wealth of plasmid sequence data [8], our knowledge of the factors which allow plasmids to maintain antibiotic resistance genes, to remain stable in bacterial populations in the absence of selective pressure, and to successfully spread to different bacterial strains is very poor.

In elementary terms the evolutionary success of a plasmid is reliant on (1) the ability to transfer vertically to daughter cells of the host bacterial strain, therefore remaining stable within this population; and/or (2) the ability to transfer horizontally to alternative bacterial hosts via conjugation [9]. Vertical stability can be ensured by the presence of an addiction system such as toxin-antitoxin systems [10]; by lack of a fitness cost conferred by the plasmid [11]; by action of an active plasmid partitioning system [12]; and/or by providing beneficial attributes such as antibiotic resistance or adhesive properties to the host providing a competitive advantage [13]. Effective horizontal transmission is associated with the frequency with which a plasmid can pass between strains and become established in a host strain after conjugation under different environmental conditions [14].

Previously, we sequenced and characterised an IncK plasmid, denoted $\mathrm{pCT}$, isolated from scouring calves [15-17]. Although it was initially identified in E. coli animal isolate, the ca. $94 \mathrm{~kb}$ plasmid carrying a single antibiotic resistance gene ( $\left.b l a_{\mathrm{CTX}-\mathrm{M}-14}\right)$ was shown to have disseminated worldwide in bacteria from humans and animals [15] and to stably persist in the host population in the absence of antibiotic pressure $[15,18]$. Inactivation of the antibiotic resistance gene (bla $\left.a_{\mathrm{CTX}-\mathrm{M}-14}\right)$ on $\mathrm{pCT}$ also had no effect on the plasmid or bacterial host biology in the absence of selective antibiotic pressure [18]. Therefore, we proposed that alternative plasmid encoded factors were responsible for the successful persistence and global distribution of $\mathrm{pCT}$. In order to test this hypothesis, we used an inactivation technique adapted from a novel gene inactivation method previously used on multi-copy plasmids $[18,19]$ to systematically inactivate candidate genes and operons previously associated with 'plasmid success'. Using a functional genomic approach analogous to that which has been broadly employed in studying chromosomal genes of various eukaryotic and prokaryotic organisms, we examined the impact of plasmid genes on $\mathrm{PCT}$ persistence and conjugation and upon the bacterial host.

\section{Results and discussion}

\section{Inactivation of six selected genes}

Based upon our previous work $[15,18]$, six loci on pCT were identified as candidates predicted to encode fundamental factors contributing to the success of this plasmid. Comparative genomics with other characterised Incompatibility group I plasmids (including IncI, IncB, IncK and IncZ) identified: a region of pCT encoding a toxin-antitoxin addiction system, pndACB (pCT_065) which we hypothesised to be involved in stable inheritance of the plasmid into daughter cells [20]; operons involved in plasmid conjugation, the tra and pil loci (pCT_068 and pCT_103) [21] including a gene likely to determine mating pair recipient specificity, shufflon recombinase gene rci (pCT_093) [22]; an unusual putative sigma 70 factor (pCT_066) and a putative parB gene involved in plasmid segregation (pCT_057) [15]. Therefore, the effects of inactivating the pndACB operon, $r c i$, pCT_066 and key structural pilus protein genes traY (tra locus), pils (pil locus) and the putative parB gene were investigated to establish the role of each element in plasmid 'success' (Figure 1).

Each gene was inactivated by homologous recombination using hybrid amplimers encoding an aph cassette encoding kanamycin resistance, flanked by regions homologous to the target. Mutants were created within an intermediate Lambda Red recombinase encoding E. coli SW102 host [23] and confirmed by sequencing across the mutated region to ensure the aph cassette has been inserted to inactivate the target gene. All six recombinant plasmids were then transformed into E. coli $\mathrm{DH} 5 \alpha$, and transferred to $S$. Typhimurium SL1344 to prevent further recombination events and for further analysis.

\section{Inactivation of the six genes had no effect on PCT maintenance}

Both wild-type $\mathrm{pCT}$ and each of the recombinant $\mathrm{pCT}$ plasmids remained stable over the investigated time period (approx. 80 generations) in $100 \%$ of both E. coli DH5 $\alpha$ and $S$. Typhimurium SL1344 host cells (Table 1). These data indicate that none of the six selected $\mathrm{pCT}$ genes are individually responsible for the short term

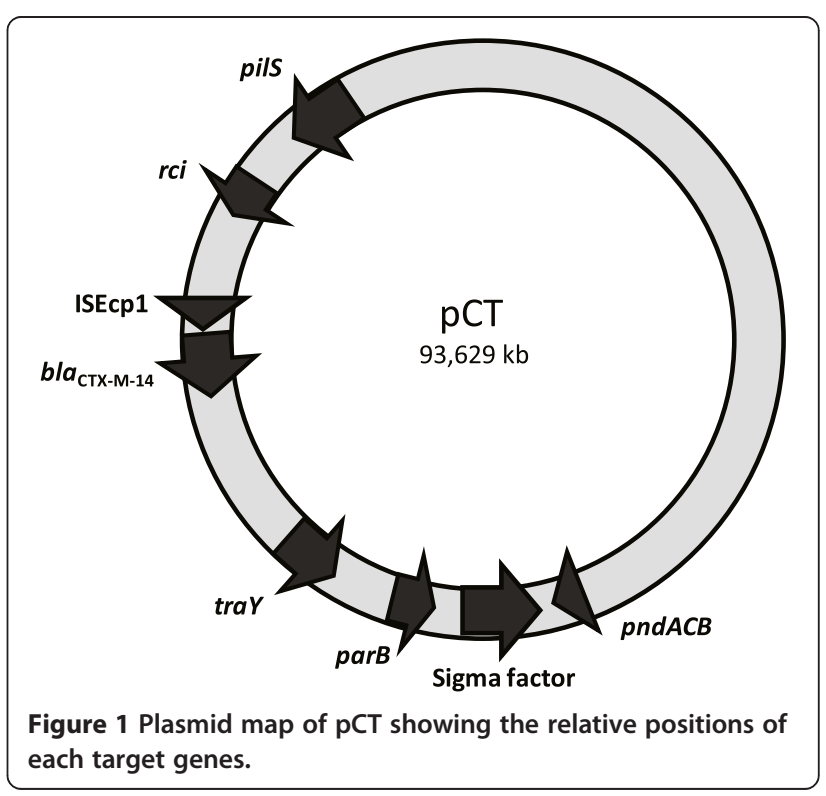


Table 1 Comparison of recombinant plasmids with wildtype PCT plasmid

\begin{tabular}{|c|c|c|c|c|c|c|}
\hline $\begin{array}{l}\text { Gene inactivated } \\
\text { on } \mathrm{pCT}\end{array}$ & Stability & $\begin{array}{l}\text { Conjugation to } \\
\text { an E. coli recipient }\end{array}$ & $\begin{array}{l}\text { Conjugation to a } \\
\text { Salmonella recipient }\end{array}$ & $\begin{array}{l}\text { Bacterial host } \\
\text { growth kinetics }\end{array}$ & $\begin{array}{l}\text { Biofilm } \\
\text { formation }\end{array}$ & $\begin{array}{l}\text { Competitive index when } \\
\text { co-cultured with WT pCT }\end{array}$ \\
\hline Sigma factor::aph & $=$ & $=$ & $=$ & $=$ & $=$ & 1.00 \\
\hline pils::aph & $=$ & $\downarrow$ & $\downarrow$ & $=$ & $=$ & 1.00 \\
\hline traY::aph & $=$ & UD & UD & $=$ & $=$ & 0.99 \\
\hline rci:aph & $=$ & $=$ & $\downarrow$ & $=$ & $=$ & 0.99 \\
\hline pndACB::aph & $=$ & $=$ & $=$ & $=$ & $=$ & 1.00 \\
\hline parB::aph & $=$ & ND & ND & $=$ & $=$ & ND \\
\hline
\end{tabular}

$=$, the same as wild-type (WT) $p C T$; $\downarrow$, reduced rate when compared to $\mathrm{pCT}$; ND, not determined; UD, Undetectable.

maintenance and successful vertical transfer of this plasmid, as their inactivation did not impact on the inheritance of $\mathrm{pCT}$. The pndACB operon is homologous to known and characterised systems in other plasmids, such as R64, R483, p026-vir, Collb-P9 and pO113, with protein identity between $91 \%$ and $100 \%$. Furuya and Komano (1996) showed that when the pndACB operon, similar to that found on the IncI plasmid R64 was inactivated, R64 was rapidly lost from the bacterial population, therefore it was required for maintenance of R64 over a similar time period [24]. Based on protein homology, plasmid $\mathrm{pCT}$ was found to encode a putative parB-like nuclease gene which shares $100 \%$ identity to a previously characterised ParB protein in p026-vir. However, the putative parB gene on $\mathrm{pCT}$ shares no significant homology to the parB DNA sequences from other IncI plasmids, such as R64 and CoIIb-P9. We found that the recombinant $\mathrm{pCT}$ plasmid carrying the inactivated putative $\operatorname{parB}$ gene also showed no significant difference in stability when compared to the wild-type plasmid. This was in contrast to work by others with plasmid P1, which showed that an intact parB is essential for the stable partitioning of P1 [25]. Our data with pCT indicated that neither pndACB nor the putative parB genes are individually essential for pCT stability under conditions tested suggesting they may not be expressed under such conditions; may work in conjunction with other elements; or are non-essential for stability due to the presence of other currently unidentified genes or gene regions. These data also suggest that broad conclusions about gene function cannot be extrapolated from data obtained with other plasmids.

The relative contribution of each conjugation pilus in $\mathrm{PCT}$ horizontal transfer

To investigate the contribution of the two conjugation pilus genes (tra and pil) in the dissemination of $\mathrm{pCT}$, the effects of inactivating the major structural protein genes of each pilus (traY and pilS) were assessed. Inactivation of traY prevented pCT transfer both in liquid and on solid surfaces (Figure 2) confirming the essential role of the tra locus for $\mathrm{pCT}$ conjugation under both conditions
[26]. The inactivation of thin pilus (pil) gene, pils, had no effect on the conjugation rate on solid surfaces, but reduced the frequency of $\mathrm{pCT}$ conjugation in liquid to both E. coli and S. Typhimurium recipients (Figure 2). This was in agreement with previous studies which have shown that the pil locus is required for conjugation in liquid [21,27]. Removal of an $r c i$ recombinase, which allows the recombination of shufflon elements to determine the terminal thin pilus protein and impacts on host specificity, has previously been shown to fix this region into one particular conformation [22]. Inactivation of the $\mathrm{pCT} r c i$ gene resulted in a reduced transfer rate of pCT to the $S$. Typhimurium recipient, particularly in liquid media, however there was no effect on the rate of transfer to the E. coli recipient (Figure 2). Therefore, we conclude that the thin pilus is not essential for $\mathrm{pCT}$ conjugation. However, the presence of the thin pilus consistently increased the frequency with which $\mathrm{pCT}$ conjugated into recipient host strains within liquid. It may be that production of the thin pilus provides better attachment of the mating pair in liquid, and the active shufflon region allows variation and an extended $\mathrm{pCT}$ bacteria host range as shown in R64 [24]. As inactivation of pilS had no effect on pCT transfer on a filter to $E$. coli recipients, the role of the thin pilus in conjugation on a solid surface is less clear (Figure 2, Table 1).

\section{Inactivation of pCT genes had no detected effect on various bacterial hosts}

Inactivation of the six selected genes on $\mathrm{pCT}$ in each of the recombinant plasmids had no effect on bacterial host growth rates during mid-logarithmic phase or generation time of either host when compared to hosts containing wild-type $\mathrm{pCT}$ (Table 1). Apart from the inactivated parB, each mutant plasmid also remained in a 1:1 ratio when E. coli $\mathrm{DH} 5 \alpha$ cells containing each mutant plasmid were co-cultured in competition with $E$. coli $\mathrm{DH} 5 \alpha$ containing wild-type pCT in-vitro. After approximately 80 generations, cells containing each mutant plasmid had a competition index indistinguishable from 1.0 (Table 1) indicating no fitness advantage or disadvantage over host cells containing wild-type pCT. Therefore, 

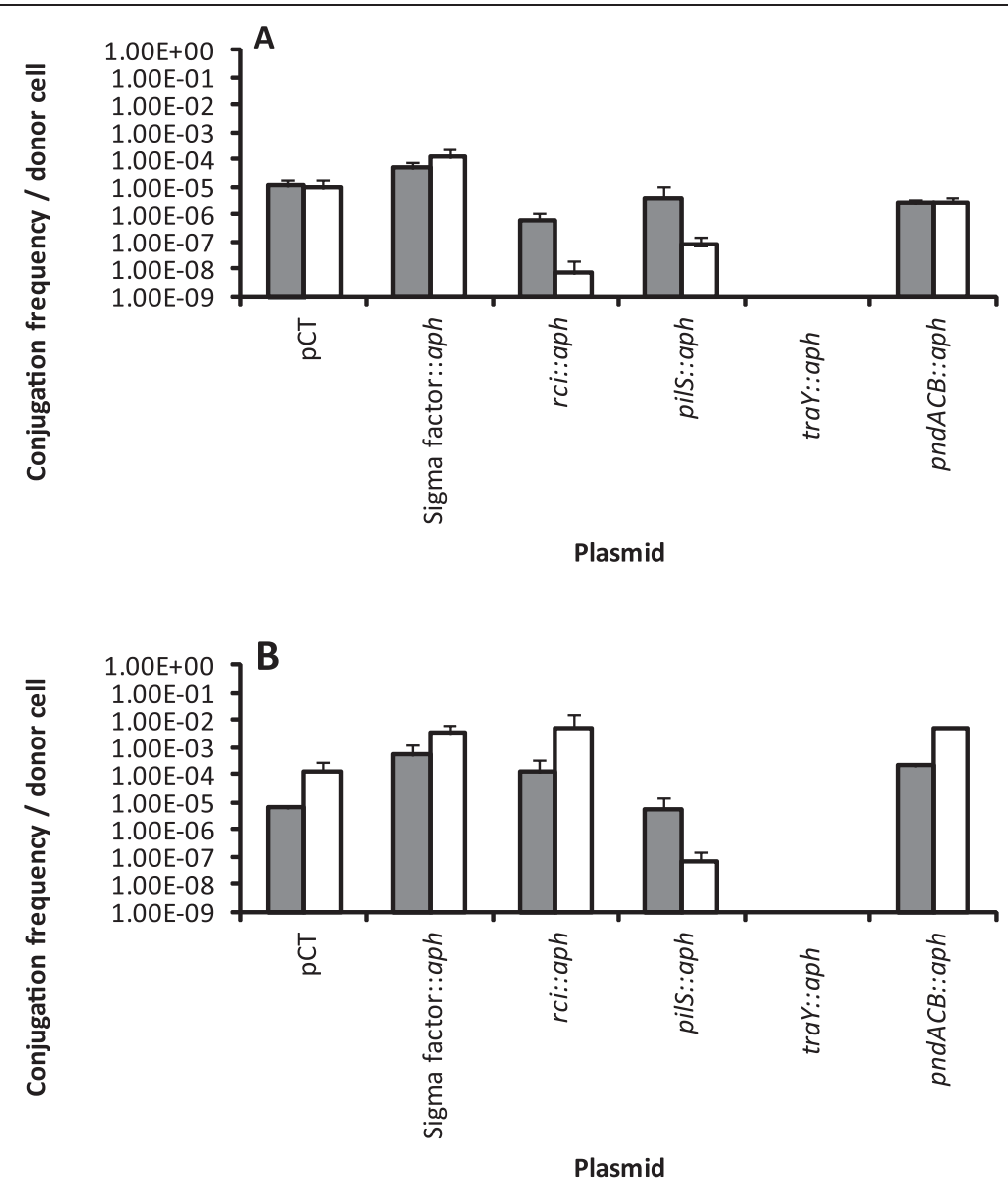

Figure 2 Conjugation frequencies of wild-type pCT and the pCT mutants on a solid surface (filled box) and in liquid (open box) from bacterial donor $E$. coli DH5a to A) a S. Typhimurium recipient and B) an E. coli recipient.

inactivation of the five selected $\mathrm{pCT}$ gene regions had neither a beneficial or detrimental effect on host growth or on the host's ability to compete in co-culture, suggesting these genes do not individually contribute or alleviate any significant burden the plasmid may place on the bacterial host cell under conditions tested. In contrast, the recombinant plasmid carrying the inactivated par $B$ gene was out-competed by the wild-type pCT plasmid. The reason behind this phenomenon is unclear as the host cells carrying this recombinant plasmid exhibited no detectable growth defect. Similarly, the recombinant plasmid showed no obvious stability problem within the host. However, we do not exclude the possibility that the recombinant plasmid carrying host may be less fit compared to the wild-type plasmid carrying host over a longer duration of competition.

Inactivation of the six loci also had no effect on the ability of host bacterial cells to form a biofilm (Table 1), suggesting that the selected genes do not contribute to the bacterial host's ability to do so. These data are in contrast to the findings of Dudley et al. (2006) who showed that inactivation of pilS on the IncK plasmid,
pSERB1, reduced the host bacterium's ability to form a biofilm by up to $50 \%$, strongly suggesting a role in biofilm formation for the pSERB1 thin pilus [13]. It maybe that other plasmid encoded factors allow for the differences in the ability of the host to form a biofilm, or that the effects on biofilm formation are host specific and only seen under particular environmental conditions. Inactivation of the putative sigma factor (pCT_066) had no detectable effect under any of the conditions tested, suggesting no role in plasmid dissemination or modulation of host bacterial fitness. Further investigation, including transcriptomic experiments are required to determine whether this sigma factor can affect the expression of plasmid or host chromosomal genes and whether our assays were not sufficiently sensitive to detect any subtle effects of removing this gene.

\section{Conclusions}

In conclusion, we postulate that the success of this plasmid is due to a combination of subtle factors rather than one particular gene or phenotypic benefit conferred to host strains. These factors include stability within a 
range of bacterial hosts (due in part to the presence of numerous genes involved in plasmid stability), a lack of a fitness burden conferred to new host strains allowing establishment of the plasmid in new hosts (shown previously) [18], and proficient conjugation allowing dissemination of $\mathrm{pCT}$ to a range of bacterial hosts in both liquid and on solid media. Although it is conventional to believe that the prudent use of antibiotic therapy would reduce the spread and dissemination of antibiotic resistance gene harbouring plasmids, our previous data have suggested otherwise [18]. We have also shown the pCT backbone to be robust in its persistence and not reliant on any single loci tested. This means that the reduction in selection pressures will not always reduce the numbers of bacteria carrying such plasmids with antibiotic resistance genes, and re-exposure to antibiotics will likely amplify the numbers of these antibiotic resistant strains. There is still much to learn about the complex nature of plasmid and bacterial host strain interactions with regard to plasmid functions, such as conjugation, stability and the overall evolutionary fitness of plasmids with their host in different conditions. However, we have shown that the functional genomic approaches we used in our study provide an example of how to use plasmid genomic data to explore fundamental and applied biological questions. We have also been able to inactivate specific loci on several other, globally successful plasmids including those carrying the carbapenemases $b l a_{\mathrm{KPC}}$ and $b l a_{\mathrm{NDM}-1}$, illustrating the utility of our approach and its broad applicability to the study of plasmid gene function (manuscripts in preparation). Recent advances in sequencing have identified various 'successful' plasmids such as those found associated with the globally disseminated strain E. coli ST131 [7] or those carrying other prominent resistance genes such as $b l a_{\mathrm{CMY}-2}$ or $b l a_{\mathrm{NDM}-1}$. Investigating the factors key to their dissemination could also be examined using a similar approach $[28,29]$. A better understanding of the biological relevance of plasmid 'backbone' genes in the successful survival and spread of antibiotic resistance plasmids will be of paramount importance if we are to prevent future persistence and further spread of both plasmid vectors and the antibiotic resistance genes that they carry.

\section{Methods}

\section{Bacterial strains and plasmid extraction}

Wild-type plasmid pCT [Genbank: FN868832] was isolated from a veterinary E. coli strain C159/11 $[15,16]$. Wild-type pCT and recombinant pCT DNA was extracted using a QIAprep Spin Miniprep Kit (Qiagen, Germany) and a QIAGEN Large Construct Kit (Qiagen, Germany) according to the manufacturers' instructions. All plasmids were transformed into $E$. coli $\mathrm{DH} 5 \alpha$ electro-competent cells (Bioline, UK) $(1.25 \mathrm{kV}, 25 \mu \mathrm{F}, 200 \Omega$, in chilled $2 \mathrm{~mm}$ electroporation cuvettes) and transformants selected by growing on agar containing $8 \mathrm{mg} / \mathrm{L}$ of cefotaxime (Sigma-Aldrich, USA) or $50 \mathrm{mg} / \mathrm{L}$ of kanamycin (SigmaAldrich, USA) when the aph cassette is used for gene inactivation.

\section{Inactivation of the six selected $\mathrm{pCT}$ genes}

To inactivate the six selected $\mathrm{pCT}$ genes, $\mathrm{pCT}$ was transformed into the E. coli strain, SW102 which carried a chromosomal Lambda-Red Recombinase [23]. Where transformation of the plasmid into this strain is difficult, conjugation by filter mating was done by selecting the transconjugants on media containing $50 \mathrm{mg} / \mathrm{L}$ of tetracycline and $8 \mathrm{mg} / \mathrm{L}$ of cefotaxime. The hybrid primers used to inactivate the selected $\mathrm{pCT}$ genes were designed to have 20 bp identity to the aph cassette on pKD4 [30] and $40 \mathrm{bp}$ sequence identity to the target genes (Table 2). Recombination of amplimers encoding the aph gene with each $\mathrm{pCT}$ gene was carried out as previously described [18]. Recombination was confirmed in each case by PCR and sequencing across the mutated DNA region (Table 2). The recombinant plasmid was then extracted and electroporated into DH5 $\alpha$ or conjugated into another host strain to avoid further recombination from occurring and for further study.

\section{Conjugation rates}

The conjugation rate of recombinant plasmids was measured on a filter (Whatman, USA) placed on an LB agar plate and in $\mathrm{LB}$ broth incubated at $37^{\circ} \mathrm{C}$ with shaking at $180 \mathrm{rpm}$ for three hours as previously described [31]. A rifampicin resistant E. coli (DH5 $\alpha)$ and S. Typhimurium (SL1344) were used as recipient strains and selection of transconjugants on LB agar containing $100 \mathrm{mg} / \mathrm{L}$ rifampicin and $8 \mathrm{mg} / \mathrm{L}$ cefotaxime (and $50 \mathrm{mg} / \mathrm{L}$ of kanamycin). Conjugation frequencies were determined on three separate occasions. Unpaired Student's $t$-tests were used to determine whether any significant changes were observed in the conjugation frequency $(p<0.05)$. The conjugation rate of the parB mutant was not determined due to the confounding effects arising from its instability. This made accurate measurements of plasmid transfer difficult due to an inability to identify host strains which have lost the plasmid.

\section{Ability to form biofilm}

The ability of strains containing each plasmid to form a biofilm was evaluated using crystal violet staining of biofilms formed over 48 hours at $30^{\circ} \mathrm{C}$ as previously described [32]. Optical density at $600 \mathrm{~nm}$ was measured to quantify the amount of biofilm produced on three separate occasions using three biological replicates with four technical replicates each in every experiment. A significant difference was determined by Student's $t$-test where $p$ value was less than 0.05 . 
Table 2 Primers used in the construction and confirmation of recombinant pCT plasmids

\begin{tabular}{|c|c|c|c|}
\hline pCT gene & Description & Primer sequence & Amplimer size (bp) (WT/inactivation) \\
\hline \multirow{4}{*}{ Sigma factor pCT_066 } & Confirmation forward & ACAGCGTCTTCTCGTATCCA & $1289 / 1675$ \\
\hline & Confirmation reverse & GTTCTTCCAGCTGACGTAAC & $1289 / 1675$ \\
\hline & Recombination 1 & GGAGGGCGTCTCGCTAAAAAAACTTACTCAAACACATCAAGTGTAGGCTGGAGCTGCTTC & 1574 \\
\hline & Recombination 2 & GCATTACTITTATTCTCGTGAGACTCAAGGTCATTCGGTGGGAATTAGCCATGGTCCAT & 1574 \\
\hline \multirow{4}{*}{ rci } & Confirmation forward & AAGGTCATCTGCAGGAGT & $945 / 1867$ \\
\hline & Confirmation reverse & GTGTCGCAGCAACAATA & $945 / 1867$ \\
\hline & Recombination 1 & GGGGGACATGCCGTATGAATCCTGTTGAACTGGTCCGAAAGTGTAGGCTGGAGCTGCTTC & 1574 \\
\hline & Recombination 2 & GCAGTGTCACGACAAACAGCCCGTTTCTGCACCCGACAGTGGGAATTAGCCATGGTCCAT & 1574 \\
\hline \multirow{4}{*}{ pils } & Confirmation forward & GCGGAAGGAAGTGAGCATAA & $722 / 2053$ \\
\hline & Confirmation reverse & CAGTGACATGCTGAAGCAGT & $722 / 2053$ \\
\hline & Recombination 1 & TGGTGACCAGATCAATACAGTTITCTTCGGCACATTGCTGTGTAGGCTGGAGCTGCTTC & 1574 \\
\hline & Recombination 2 & AACCTGCAGACAATCGCCACCAAAATGAAAGCCCAGAAAGGGAATTAGCCATGGTCCAT & 1574 \\
\hline \multirow{4}{*}{ traY } & Confirmation forward & GGAGAGTCCGGTCTGTATGA & $2423 / 2138$ \\
\hline & Confirmation reverse & TGCAACCAGTGTGGTACAG & $2423 / 2138$ \\
\hline & Recombination 1 & GTATCCTGGTCTGCCTGTTACTGATGAGTACCATTGCAGCGTGTAGGCTGGAGCTGCTTC & 1574 \\
\hline & Recombination 2 & CGGCACAAAACAGCAAAAACAGCAGGAAGTAGAGTGGTGGGGGAATTAGCCATGGTCCAT & 1574 \\
\hline \multirow{4}{*}{ pndACB } & Confirmation forward & AAGGATTGTGGCGGACAGGA & $486 / 1288$ \\
\hline & Confirmation reverse & TGATGACGCACAGGACGGAA & $486 / 1288$ \\
\hline & Recombination 1 & CCCAGGCGATTTTTTATCAATCAACCCAGGGCCCACTGTGTGTAGGCTGGAGCTGCTTC & 1574 \\
\hline & Recombination 2 & ATTGAGGTCAGCCTTCGCAACAATCCGGCGGCAGATGTCCGGGAATTAGCCATGGTCCAT & 1574 \\
\hline \multirow{4}{*}{ parB } & Confirmation forward & TATTAAAAATAACGCGGCGG & $663 / 1872$ \\
\hline & Confirmation reverse & GCAAAGTATCACACTGCCAAAA & $663 / 1872$ \\
\hline & Recombination 1 & GGAGCGGCGGGAGAGTATAGTCATTATTGTAGTCCGGGTAGTGTAGGCTGGAGCTGCTTC & 1574 \\
\hline & Recombination 2 & CTTTCACTCACCATTATTTTTCCGCTTCTCTCTGTGCCGGGAATTAGCCATGGTCCAT & 1574 \\
\hline
\end{tabular}




\section{Growth kinetics}

Growth of each bacterial strain containing both wildtype $\mathrm{pCT}$ and the recombinant plasmids was determined by monitoring the optical density of bacterial cultures at a wavelength of $600 \mathrm{~nm}$ in LB broth in a FLUOstar OPTIMA (BMG Labtech, UK) as previously described [33]. The growth kinetics were repeated at least three times with three biological replicates per strain in each experiment and the differences were analysed using unpaired Student's $t$-test. Differences were significant when $p$ value was less than 0.05 .

\section{Plasmid persistence}

Stability of the mutant plasmids was measured by assessing the proportion of cells that carry each plasmid over time within LB broth isogenic cultures incubated at $37^{\circ} \mathrm{C}$ with shaking at $180 \mathrm{rpm}$. At 12, 24, 48 and 72 hours, $100 \mu \mathrm{l}$ of culture was used to inoculate fresh prewarmed LB broth at a dilution of 1:100. Viable counts were determined every two hours for the first 12 hours and then at 24, 48, 72 and 96 hours. Colonies from each viable count were replica plated onto antibiotic free and antibiotic containing agar plates $(8 \mathrm{mg} / \mathrm{L}$ of cefotaxime or $50 \mathrm{mg} / \mathrm{L}$ kanamycin). Colonies growing on the antibiotic free plate but not on the antibiotic containing plates indicated the proportion of bacteria that had lost the plasmid. The experiment was repeated on three separate occasions using three biological replicates of each strain on each occasion.

\section{Pair-wise competitive growth}

A pair-wise competition assay in-vitro was used to determine whether inactivation of the six genes on $\mathrm{pCT}$ impacted upon the ability of the plasmid to persist when competed within a culture with cells containing wildtype pCT. Overnight bacterial cultures of DH5 $\alpha$ pCT and $\mathrm{DH} 5 \alpha$ containing the five $\mathrm{pCT}$ mutant plasmids were used to seed fresh LB broth in a 1:1 ratio and grown at $37^{\circ} \mathrm{C}$ with shaking at $180 \mathrm{rpm}$. A viable count was performed every two hours and cultures were used to seed fresh broth every 24 hours for a period of 4 days. Colonies from the viable count were replica plated onto LB agar plates containing 1) cefotaxime $8 \mathrm{mg} / \mathrm{L}, 2)$ kanamycin $50 \mathrm{mg} / \mathrm{L}$, and 3) no antibiotic. The proportion of each plasmid in each culture was determined at each time point by counting the number of colonies on each of the antibiotic selective plates and calculating the proportion of each test plasmid accordingly. The competition index was defined as $1+\left(\left[\log _{10} \mathrm{~A}-\log _{10} \mathrm{~B}\right] /\right.$ number of generations) modified from Pope et al. (2010) [34], where $\mathrm{A}$ is the ratio of the plasmids at 72 hours (including four passages), $B$ is the ratio at the beginning of the assay, a competitive index of 1 indicates no competitive advantage nor disadvantage within the assay.

\section{Competing interests}

The authors declare that they have no competing interests.

\section{Authors' contributions}

JLC and HTHS carried out the experiments and analysed the data. All authors contributed to writing of the manuscript. Experimental strategy was carried out by MAW and LJVP who also supervised the project. All authors read and approved the final manuscript.

\section{Authors' information}

Jennifer L Cottell and Howard TH Saw: joint first authors.

\section{Acknowledgments}

We are thankful for the contribution of Vito Ricci and Grace Adams towards the completion of this project.

Received: 27 February 2014 Accepted: 19 June 2014

Published: 24 June 2014

\section{References}

1. Johnson TJ, Nolan LK: Pathogenomics of the virulence plasmids of Escherichia coli. Microbiol Mol Biol Rev 2009, 73(4):750-774.

2. van Hoek AH, Mevius D, Guerra B, Mullany P, Roberts AP, Aarts HJ: Acquired antibiotic resistance genes: an overview. Front Microbiol 2011, 2:203.

3. Hawkey PM, Jones AM: The changing epidemiology of resistance. J Antimicrob Chemother 2009, 64(suppl 1):i3-i10.

4. Piddock $L V$ : The crisis of no new antibiotics - what is the way forward? Lancet Infect Dis 2012, 12(3):249-253.

5. Hawkey PM: The growing burden of antimicrobial resistance. J Antimicrob Chemother 2008, 62(Suppl 1):i1-i9.

6. Walsh TR, Weeks J, Livermore DM, Toleman MA: Dissemination of NDM-1 positive bacteria in the New Delhi environment and its implications for human health: An environmental point prevalence study. Lancet Infect Dis 2011, 11(5):355-362.

7. Woodford N, Carattoli A, Karisik E, Underwood A, Ellington MJ, Livermore DM: Complete nucleotide sequences of plasmids pEK204, pEK499, and pEK516, encoding CTX-M enzymes in three major Escherichia coli lineages from the United Kingdom, all belonging to the international O25:H4-ST131 clone. Antimicrob Agents Chemother 2009, 53(10):4472-4482.

8. Genome pages - plasmid. http://www.ebi.ac.uk/genomes/plasmid.html

9. Turner PE, Cooper VS, Lenski RE: Tradeoff between horizontal and vertical modes of transmission in bacterial plasmids. Evolution 1998, 52(2):315-329.

10. Hayes F: Toxins-antitoxins: plasmid maintenance, programmed cell death, and cell cycle arrest. Science 2003, 301(5639):1496-1499.

11. Dahlberg C, Chao L: Amelioration of the cost of conjugative plasmid carriage in Eschericha coli K12. Genetics 2003, 165(4):1641-1649.

12. Salje J: Plasmid segregation: how to survive as an extra piece of DNA. Crit Rev Biochem Mol Biol 2010, 45(4):296-317.

13. Dudley EG, Abe C, Ghigo JM, Latour-Lambert P, Hormazabal JC, Nataro JP: An Incl1 plasmid contributes to the adherence of the atypical enteroaggregative Escherichia coli strain C1096 to cultured cells and abiotic surfaces. Infect Immun 2006, 74(4):2102-2114.

14. Waters VL: Conjugative transfer in the dissemination of beta-lactam and aminoglycoside resistance. Front Biosci 1999, 4:D433-D456.

15. Cottell $J \mathrm{~L}$, Webber MA, Coldham NG, Taylor DL, Cerdeno-Tarraga AM, Hauser $H$, Thomson NR, Woodward MJ, Piddock LJ: Complete sequence and molecular epidemiology of IncK epidemic plasmid encoding blaCTX-M-14. Emerg Infect Dis 2011, 17(4):645-652.

16. Liebana E, Batchelor M, Hopkins KL, Clifton-Hadley FA, Teale CJ, Foster A Barker L, Threlfall EJ, Davies RH: Longitudinal farm study of extended-spectrum beta-lactamase-mediated resistance. J Clin Microbiol 2006, 44(5):1630-1634.

17. Teale CJ, Barker L, Foster AP, Liebana E, Batchelor M, Livermore DM, Threlfall EJ: Extended-spectrum beta-lactamase detected in $E$ coli recovered from calves in Wales. Vet Rec 2005, 156(6):186-187.

18. Cottell $J$ L, Webber MA, Piddock $\amalg$ : Persistence of transferable ESBL resistance in the absence of antibiotic pressure. Antimicrob Agents Chemother 2012, 56(9):4703-4706. 
19. Thomason LC, Costantino N, Shaw DV, Court DL: Multicopy plasmid modification with phage lambda Red recombineering. Plasmid 2007, 58(2):148-158

20. Nielsen $A K$, Gerdes K: Mechanism of post-segregational killing by hok-homologue pnd of plasmid R483: two translational control elements in the pnd mRNA. J Mol Biol 1995, 249(2):270-282.

21. Bradley DE: Characteristics and function of thick and thin conjugative pili determined by transfer-derepressed plasmids of incompatibility groups I1, 12, 15, B, K and Z. J Gen Microbiol 1984, 130(6):1489-1502.

22. Komano T, Kim SR, Yoshida T: Mating variation by DNA inversions of shufflon in plasmid R64. Adv Biophys 1995, 31:181-193.

23. Sharan SK, Thomason LC, Kuznetsov SG, Court DL: Recombineering: a homologous recombination-based method of genetic engineering. Nat Protoc 2009, 4(2):206-223.

24. Furuya $\mathrm{N}$, Komano T: Nucleotide sequence and characterization of the trbABC region of the Incl1 plasmid R64: existence of the pnd gene for plasmid maintenance within the transfer region. J Bacterio/ 1996, 178(6):1491-1497.

25. Friedman $\mathrm{SA}$, Austin SJ: The P1 plasmid-partition system synthesizes two essential proteins from an autoregulated operon. Plasmid 1988, 19(2):103-112.

26. Komano T, Yoshida T, Narahara K, Furuya N: The transfer region of Incl1 plasmid R64: similarities between R64 tra and Legionella i $\mathrm{cm} /$ dot genes. Mol Microbiol 2000, 35(6):1348-1359.

27. Yoshida T, Kim SR, Komano T: Twelve pil genes are required for biogenesis of the R64 thin pilus. J Bacteriol 1999, 181(7):2038-2043.

28. Call DR, Singer RS, Meng D, Broschat SL, Orfe LH, Anderson JM, Herndon DR, Kappmeyer LS, Daniels JB, Besser TE: blaCMY-2-positive IncA/C plasmids from Escherichia coli and Salmonella enterica are a distinct component of a larger lineage of plasmids. Antimicrob Agents Chemother 2010, 54(2):590-596.

29. Potron A, Poirel L, Nordmann P: Plasmid-mediated transfer of the blaNDM-1 gene in Gram-negative rods. FEMS Microbiol Lett 2011, 324(2):111-116.

30. Datsenko KA, Wanner BL: One-step inactivation of chromosomal genes in Escherichia coli K-12 using PCR products. Proc Natl Acad Sci U S A 2000, 97(12):6640-6645.

31. Hartskeerl R, Zuidweg E, van Geffen M, Hoekstra W: The Incl plasmids R144, R64 and Collb belong to one exclusion group. J Gen Microbiol 1985, 131(6):1305-1311.

32. Baugh S, Ekanayaka AS, Piddock $L$, Webber MA: Loss of or inhibition of all multidrug resistance efflux pumps of Salmonella enterica serovar Typhimurium results in impaired ability to form a biofilm. J Antimicrob Chemother 2012, 67(10):2409-2417.

33. Webber MA, Randall LP, Cooles S, Woodward MJ, Piddock LV: Triclosan resistance in Salmonella enterica serovar Typhimurium. J Antimicrob Chemother 2008, 62(1):83-91.

34. Pope CF, Gillespie SH, Moore JE, McHugh TD: Approaches to measure the fitness of Burkholderia cepacia complex isolates. J Med Microbiol 2010, 59(Pt 6):679-686.

doi:10.1186/1471-2180-14-168

Cite this article as: Cottell et al:: Functional genomics to identify the factors contributing to successful persistence and global spread of an antibiotic resistance plasmid. BMC Microbiology 2014 14:168.

\section{Submit your next manuscript to BioMed Central and take full advantage of:}

- Convenient online submission

- Thorough peer review

- No space constraints or color figure charges

- Immediate publication on acceptance

- Inclusion in PubMed, CAS, Scopus and Google Scholar

- Research which is freely available for redistribution

Submit your manuscript at www.biomedcentral.com/submit 